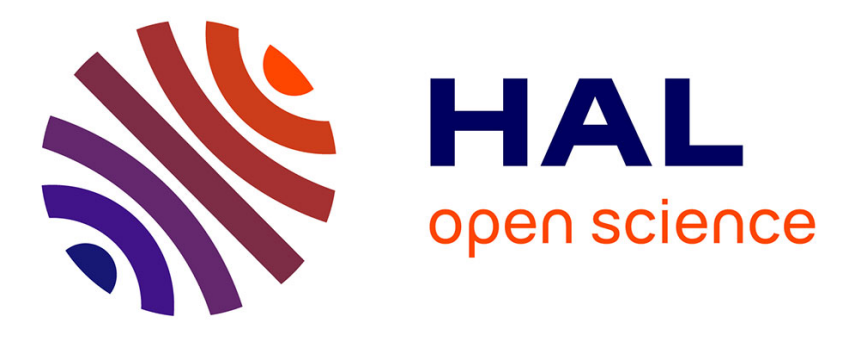

\title{
Multiangle Light Scattering and Viscometric Detector for Size-Exclusion Chromatography
}

Jean-Pierre Busnel, Christophe Degoulet, Taco Nicolai, William Woodley, Patrick Patin

\section{- To cite this version: \\ Jean-Pierre Busnel, Christophe Degoulet, Taco Nicolai, William Woodley, Patrick Patin. Multiangle Light Scattering and Viscometric Detector for Size-Exclusion Chromatography. Journal de Physique III, 1995, 5 (10), pp.1501-1512. 10.1051/jp3:1995207 · jpa-00249398}

\section{HAL Id: jpa-00249398 https://hal.science/jpa-00249398}

Submitted on 1 Jan 1995

HAL is a multi-disciplinary open access archive for the deposit and dissemination of scientific research documents, whether they are published or not. The documents may come from teaching and research institutions in France or abroad, or from public or private research centers.
L'archive ouverte pluridisciplinaire $\mathbf{H A L}$, est destinée au dépôt et à la diffusion de documents scientifiques de niveau recherche, publiés ou non, émanant des établissements d'enseignement et de recherche français ou étrangers, des laboratoires publics ou privés. 
Classification

Physics Abstracts

$36.20 \mathrm{CW}-82.80 \mathrm{Bg}-33.80-\mathrm{b}-06.50-\mathrm{x}$

\title{
Multiangle Light Scattering and Viscometric Detector for Size- Exclusion Chromatography
}

\author{
Jean-Pierre Busnel $\left({ }^{1}\right)$, Christophe Degoulet $\left({ }^{1}\right)$, Taco Nicolai $\left({ }^{1}\right)$, William Woodley $\left({ }^{2}\right)$ \\ and Patrick Patin $\left({ }^{2}\right)$
}

( ${ }^{1}$ ) Laboratoire de Physico-Chimie Macromoleculaire, CNRS URA 509, Université du Maine, Avenue Olivier Messiaen, BP 535, 72017 Le Mans Cedex, France

$\left({ }^{2}\right)$ SEMAtech, Chemin de Terron, 06200 Nice, France

(Received 27 March 1995, revised 29 May 1995, accepted 3 July 1995)

\begin{abstract}
A new miniaturised Light Scattering (LS) apparatus coupled with a capillary viscometer has been developed which analyses sequentially small size fractions of eluent $\left(1 \mathrm{~cm}^{3}\right)$. The apparatus can be used in an autonomous manner in order to obtain the weight-average molar mass $\left(M_{\mathrm{w}}\right)$, the $z$-average radius of gyration $\left(R_{\mathrm{g}}\right)$, the second virial coefficient $\left(A_{2}\right)$, the intrinsic viscosity $([\eta])$ and the Huggins constant $(k)$ by analysing a given polymer sample at different concentrations. The device can be coupled to a standard Size-Exclusion Chromatography chain in which the detector not only provides mean values, but also the evolution of $[\eta], M_{\mathrm{w}}$ and $R_{\mathrm{g}}$ as a function of elution volume $\left(V_{\mathrm{e}}\right)$. Specific calibration curves $\left(\log \left(M_{\mathrm{w}}\right)=f\left(V_{\mathrm{e}}\right)\right)$ can be constructed for any sample, and then be used without the combined detector. In this way the molecular weight dependence of $[\eta]$ and $R_{\mathrm{g}}$ is readily obtained. Moreover, the special design of the detector allows simple collection of fractions. A number of problems which need to be solved in order to allow an efficient use of the detector are discussed Results on polystyrene standards illustrate the good performance of the apparatus.
\end{abstract}

\section{Introduction}

SEC is a powerful tool for characterizing the molar mass distribution of polymers. Classically this method relies on a calibration using monodisperse standards and does not yield absolute molar masses. For that reason, there is an increasing interest in coupling detectors that give directly absolute values of $M_{\mathrm{w}}$.

In a first attempt Grubizic et al. [1] coupled a Capillary Viscometer (VS) to the SEC chain. The VS was filled by a siphon with volume $5 \mathrm{~cm}^{3}$ but was not adapted to modern column sets. A miniaturised version with siphon volume as low as $1 \mathrm{~cm}^{3}$ has been developed by Orvoen et al. [2].

Another approach has been to use pressure monitoring at the entrance of a capillary filled by the eluent flow just at the outlet of the column [3]. In that case, if the flow rate is perfectly stable and if laminar conditions are observed, pressure is simply proportional to viscosity. In 
order to smooth the effect of pump pulsation, a pulse dampener must be used [4]. To eliminate flow rate fluctuation a differential device has been proposed [5]. In the set-up described here the viscosity is measured in discrete steps which results in a much better signal to noise ratio than continuous measurements.

Coupling Light Scattering (LS) and Refractive Index (RI) detectors to the SEC chain became possible with availability of stable and small size laser sources [6]. The first commercial light scattering detector was developed by Chromatix, allowing on line intensity measurements at one very low scattering angle. A similar system is now available from Polymer Laboratories. A multi angle light scattering detector has been developed by Wyatt technology and more recently Precision Detector developed a two angle light scattering detector. Several investigations of polymers with SEC involving three detectors (RI, LS, VS) have already been reported in the literature, but all of them were obtained with a home-made combination.

All previously developed LS detectors are based on a miniaturised circulation cell allowing continuous measurement. This approach is a necessity when the priority is to obtain rapid examination of the sample. We have chosen for a different approach considering that the quantity of information obtained from multi detection is so large that interpretation is the most crucial part. Our aim is to obtain complete results rather than rapid results. With that priority the use of long column sets is better as it gives higher resolution.

We have developed a miniaturised Light Scattering (LS) detector coupled with a capillary viscometer, which analyses sequentially small size fractions of eluent $\left(1 \mathrm{~cm}^{3}\right)$. The device is placed after the last conventional S.E.C detector (usually differential refractometer). The design necessitates relatively long column sets (typically a set of $1.20 \mathrm{~m}$ ) to allow characterization of a sufficient number of fractions, but, as we will show, the discrete detection has a number of advantages over continuous detection.

\section{Apparatus Description}

Figure 1 shows the general organisation of the apparatus. The eluent is collected in a small reservoir, then transferred in the LS cell and finally transferred to the viscometer. Each part is thermostated by a circulation fluid. Miniaturised solenoid operated isolation valves (EV) allow transfer. To facilitate the transfer the LS cell is slightly under pressurised during filling and slightly over pressurised during emptying. To prevent splotches stainless steel tubing direct the flow near the walls. The LS cell is placed in a index matching liquid bath (filled with toluene) to eliminate reflectance at the interface glass/air. The incident light source is a 5 $\mathrm{mW}$ helium-neon laser emitting light at $633 \mathrm{~nm}$. A set of 11 Miniaturised Photomultipliers (PM, Hamamatsu, Japan, type R3811) allows simultaneous observation of the scattered light at fixed angles $(\theta=7.5,15,30,45,60,75,90,105,120,135$ and 150 degrees $)$. The lowest scattering angle can at the present stage not be used due to difficulties of the optical alignment. An optical device which collimates the image of the centre of the cell on a thin slit is placed in front of each PM, in order to control solid angle observed (Fig. 2). A common power supply (Hamamatsu, Japan, Type CEE5) assures stable conditions for these PM. A reference photodiode measures the intensity of the incident light which allows correction for fluctuations of the incident light intensity. In practice, however, these fluctuations are negligible. The signals coming from the eleven PM, from the reference photodiode and from up to three other signals (chromatographic detectors, pump . ) are treated by individual amplifiers with zero and gain adjustments. The $\mathrm{PM}$ are set to give about $100 \mathrm{mV}$ for pure toluene and are linear up to $10 \mathrm{~V}$. Data collection and transmission to a Personal Computer (PC) is accomplished by a multi-channel data processor (DAP 2400 from Microstar). The 12 bits A/D converter works at $625 \mathrm{~Hz}$ on each channel and has auto range facility. The scattered light intensities 


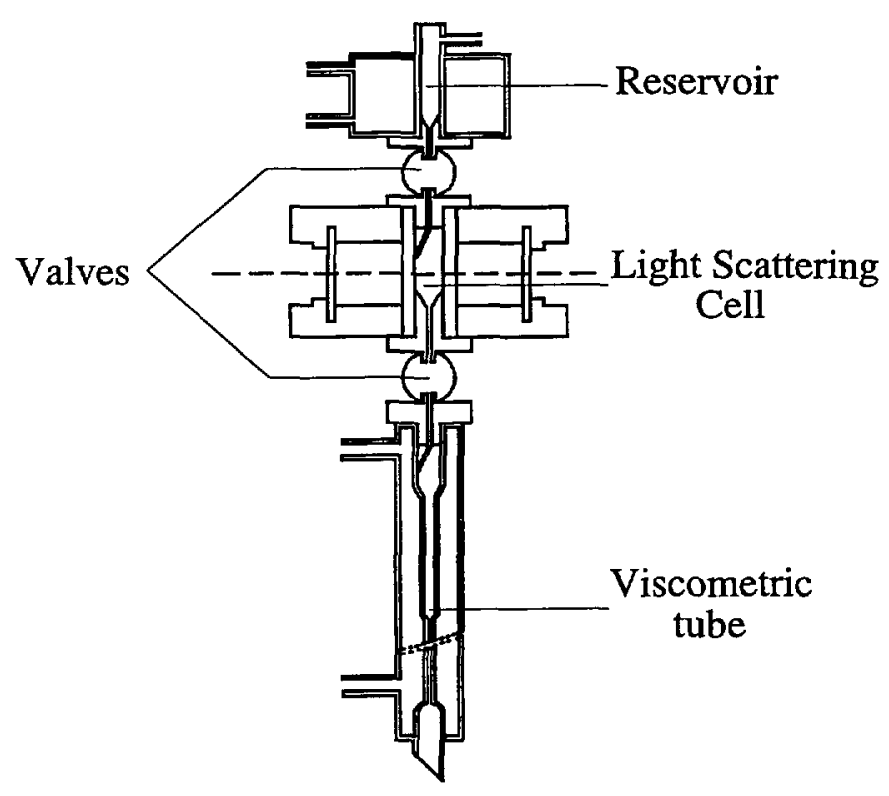

Fig. 1. - General organisation of the combined detector.

collected during a given time span (usually $1 \mathrm{~s}$ ) are stored after normalisation by the incident light intensity. Measurements of the scattered light intensity of optically clean toluene at $90^{\circ}$ show a relative standard deviation of $0.3 \%$ (over 100 successive collections of $1 \mathrm{~s}$ ).

The capillary viscometer is a standard device with a calibrated capillary tube (length $9 \mathrm{~cm}$ ) of which the diameter can be easily adapted to the viscosity of the eluent to obtain desired measurement times. We use $0.44 \mathrm{~mm}$ for THF and $0.50 \mathrm{~mm}$ for $\mathrm{H}_{2} \mathrm{O}$ which give measurement times of about $30 \mathrm{~s}$ for the pure eluent at $25^{\circ} \mathrm{C}$. The lower glass solder is very flat to give a well defined flowing height and to prevent bubble capture. Elimination of bubbles also necessitates precise positioning of the outlet tubing of the EV situated at the top of the viscometer. The upper part allows automatic time counting using a patented dual optical path detector [7]. An electronic control card, commanded by a $\mathrm{PC}$, activates the $\mathrm{EV}$ and a pump for pressurisation and gives start and stop signals. The flow times are stored on a PC. To allow stable flow time measurements, a very efficient temperature regulation and precise geometry conditions are required. After optimising all the parameters, the relative standard deviation on the flow time over 60 successive measurements of pure eluent (Water or THF) is $0.01 \%$, which is better than performances available by using a pressure monitoring viscometric detector.

For automatic measurements on line with SEC a very slow drift of the temperature is not a problem as long as only linear drift is observed during one analysis. Such a linear drift is taken into account as a base line drift and residual temperature fluctuations are less than $0.01{ }^{\circ} \mathrm{C}$. Cleanliness of the glassware is very important. The glass surface has to be wetted by the eluent. When using organic eluent (THF, Toluene) the glassware is best cleaned with an efficient detergent. When measuring aqueous solutions it is often useful to clean the surface with a strong base. In spite of these precautions it remains difficult to measure polymers with tensioactive properties, because it is not always possible to prevent the occasional formation of bubbles which perturb the measurements. 

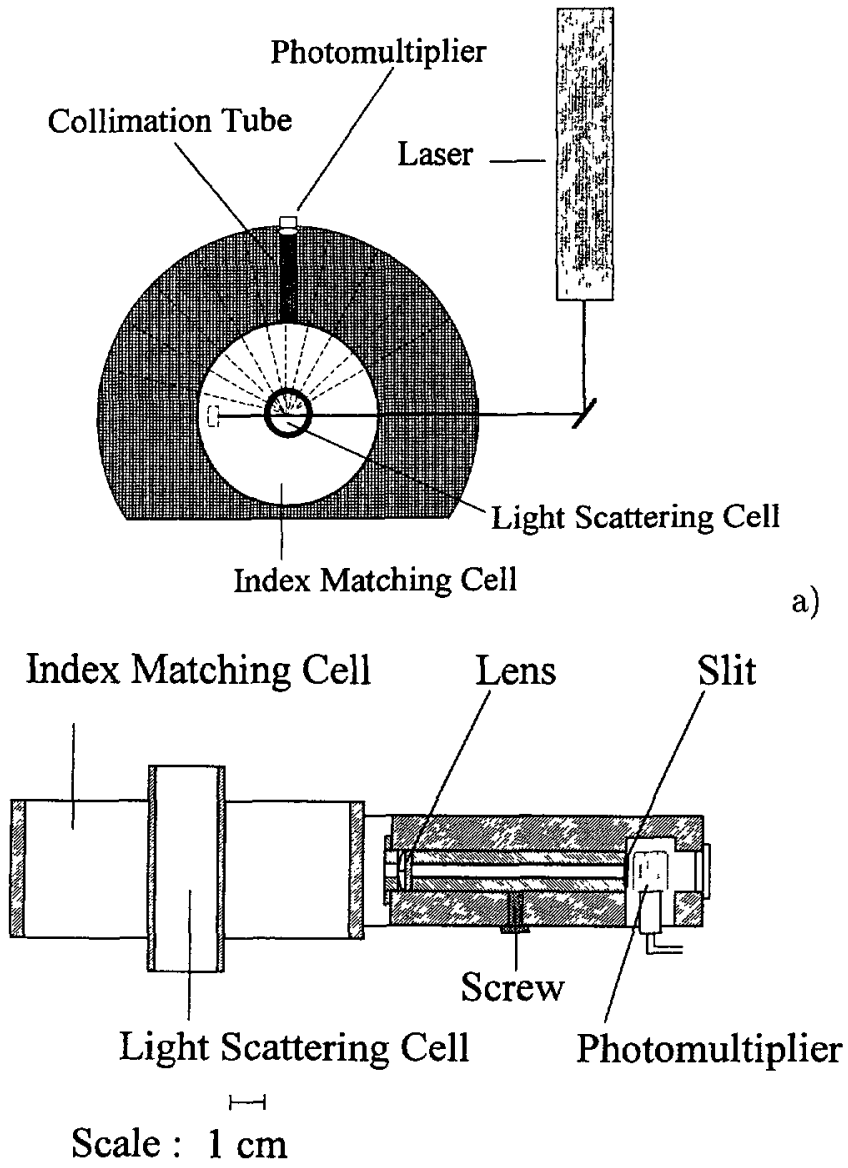

b)

Fig. 2. - a) Top View of the detector. b) Collimation tube. This device is the same for all angles.

\section{Determination of Apparatus Constants}

2.1. Determination of the Distance Between the Ri Detector and the LS DecTECTOR, AND OF THE EFFICIENCY OF Liquid TRANSFer. - For the LS and VS detection the eluent is fractionated in fractions of typically $1 \mathrm{~cm}^{3}$. The concentration, however, is continuously monitored by a RI detector so that it is necessary to determine exactly the volume between the refractometer cell and the reservoir. Furthermore, we need to know the efficiency of liquid transfer to take into account pollution of a fraction by the previous one.

The refractometer cell has a relatively wide bore to minimise any back pressure effect. For the RI used (R410 from Waters Millipore) the tubing was wrapped around a heat exchange block so the volume between the cell and the outlet was as large as $1.5 \mathrm{~cm}^{3}$. This relatively large volume produced some mixing effect and by rearranging the outlet we have reduced the volume to $0.3 \mathrm{~cm}^{3}$ without reduction of the signal to noise ratio. Exact determination of the volume is obtained by injecting a small bubble and measuring the time between injection and passage in the cell at a given flow rate. 
Handling of small amounts of liquid necessitates some precautions to reduce pollution between successive fractions. Optimisation is obtained by adjusting the time of opening EV ( $2 \mathrm{~s}$ for THF, $2.5 \mathrm{~s}$ for $\left.\mathrm{H}_{2} \mathrm{O}\right)$ and the value of the over pressure or under pressure $( \pm 2000 \mathrm{~Pa})$. To check the fraction of residual liquid after transfer $(f)$, the concentration of an absorbing solution is measured by UV at the outlet of the viscometer in two situations : either a solution of concentration $C$ is followed by pure solvent or the pure solvent is followed by a solution of concentration $C$. From those results it is possible to extract $f$ after emptying the reservoir and after emptying the cell. These two values were near 0.03 at optimised conditions.

\subsection{Calibration of the PM and Determination of the Amount of Reflectance}

The measured PM signal $Y(\theta)$ is the sum of the intensity of the light scattered by the sample $\left(I_{\mathrm{sc}}\right)$ and spuriously reflected light $\left(I_{\text {ref }}\right)$ :

$$
k(\theta) Y(\theta)=I_{\mathrm{sc}}(\theta) \sin \theta+I_{\mathrm{refl}}(\theta)
$$

Here $k(\theta)$ is a calibration factor which depends on the PM and the optical set-up and the angle of observation $\theta$. The amount of reflectance is essentially depending on the refractive index change at the glass and sample interface so $I_{\text {refl }}(\theta)$ has the same value for pure solvent and for a dilute solution of a low molar mass polymer. The difference between the signals of a dilute solution $\left(I_{\mathrm{sc}}, Y\right)$ and the pure solvent $\left(I_{0 \mathrm{sc}}, Y_{0}\right)$ is given by:

$$
k(\theta)\left(Y(\theta)-Y_{0}(\theta)\right)=\left(I_{\text {sc }}(\theta)-I_{0 s c}(\theta)\right) \sin \theta
$$

For dilute solutions of low molar mass polymers the angular dependence of $I_{\mathrm{sc}}$ may be neglected so that:

$$
\left(I_{\mathrm{sc}}(\theta)-I_{0 \mathrm{sc}}(\theta)\right) \sin \theta=I_{\mathrm{sc}}(90)-I_{0 \mathrm{sc}}(90)
$$

and

$$
\frac{k(\theta)}{k(90)}=\frac{Y(90)-Y_{0}(90)}{Y(\theta)-Y_{0}(\theta)}
$$

Values of $k(\theta)$ are found to be very stable (less than $1 \%$ drift in one month).

As the reflectance at $90^{\circ}$ is negligible the signal due to reflectance $\left(Y_{\text {reff }}\right)$ at other angle is readily obtained using:

$$
Y_{\text {refl }}(\theta)=\frac{k(\theta)}{k(90)} Y(\theta)-Y(90)
$$

For measurements in THF reflectance can be corrected down to $15^{\circ}$ without introducing large uncertainties in the experimental results, and in water the correction is valid down to $30^{\circ}$. 


\section{Operation, Data Acquisition and Data Handling}

Measurements can be done in either the manual or the automatic mode. In both modes a number of parameters which steer the experiment need to be entered in the computer.

3.1. Manual Mode. - In the manual mode it is possible to activate manually EV to allow glassware flushing. Once the sample is in the reservoir, the operator can start the following sequence: the LS cell is filled; the LS measurement is executed; the cell is emptied and the viscosity measurement is executed. During this sequence the operator can refill the reservoir for the next measurement. The number of data collected during one LS measurement depends on the duration of collection of the scattered light (usually $1 \mathrm{~s}$ ) and the total duration of the measurement (usually $1 \mathrm{~min}$ ). The LS data are treated in the following way to reduce the influence of spurious scattering. First an average value is calculated using a previously fixed percentage of the lower values. Then the average value which is used in further calculations is calculated using all data within a chosen range around the initial average. The same rejection criterion can be applied to all angles automatically or each angle can be examined individually. We have found that generally about $30 \%$ of the data are excluded if we choose a range of $\pm 2 \%$ around the average calculated using the lower $25 \%$ of the data.

If a series of concentrations is measured, the software enables one to analyse the data in the form of a so-called Zimm plot [8] and the weight average molar mass, $z$-average radius of gyration and second virial coefficient can be determined. From the concentration dependence of the flow times the intrinsic viscosity $[\eta]$ and the Huggins coefficient $k$ are computed.

3.2. Automatic Mode. - In the automatic mode the device is connected to a SEC apparatus and a large number of measurements are performed automatically on the discrete fractions of the elution volume. The rejection criteria for the pre-treatment of the LS data have to be pre-set and are the same for all angles and fractions measured during a session. Only the average LS intensities of each angle and fraction is stored. The relative excess LS intensity $\left(I_{\text {rel }}\right)$ is calculated by subtracting the solvent scattering (the baseline in the chromatograph) and normalising by the scattering of toluene. The RI signal is analysed to give the concentration as a function of elution volume. If $100 \%$ of the sample passes through the column, the refractive index increment can be calculated from the integrated RI signal area and the injected mass. If it is not sure that $100 \%$ of the sample passes, the refractive index increment needs to be determined separately. At this stage, a calibration curve can be used to calculate the molar mass as a function of the elution volume.

In a second step, the LS and VS data can be analysed. The molar mass and radius of gyration of each fraction can be calculated from the angular dependence of the average intensities using the Guinier domain. If the radii are larger than about $60 \mathrm{~nm}$ a more sophisticated analysis method involving structure factor analysis has to be used which will be discussed elsewhere [9]. An iterative procedure which takes in account the details of fraction composition positions the molar masses, the radii of gyration and the intrinsic viscosities of each fraction at precise values of the elution volume. The software enables one to take into account drifts in the baseline. In this way new calibration curves can be constructed and the molar mass distribution of the sample can be determined. In the treatment the second virial coefficient and the Huggins coefficient can be neglected as the concentrations used in SEC are usually very low. However, if these parameters are known they can of course be incorporated in the analysis.

A large number of samples can be analysed in one session by programming a series of injections. 


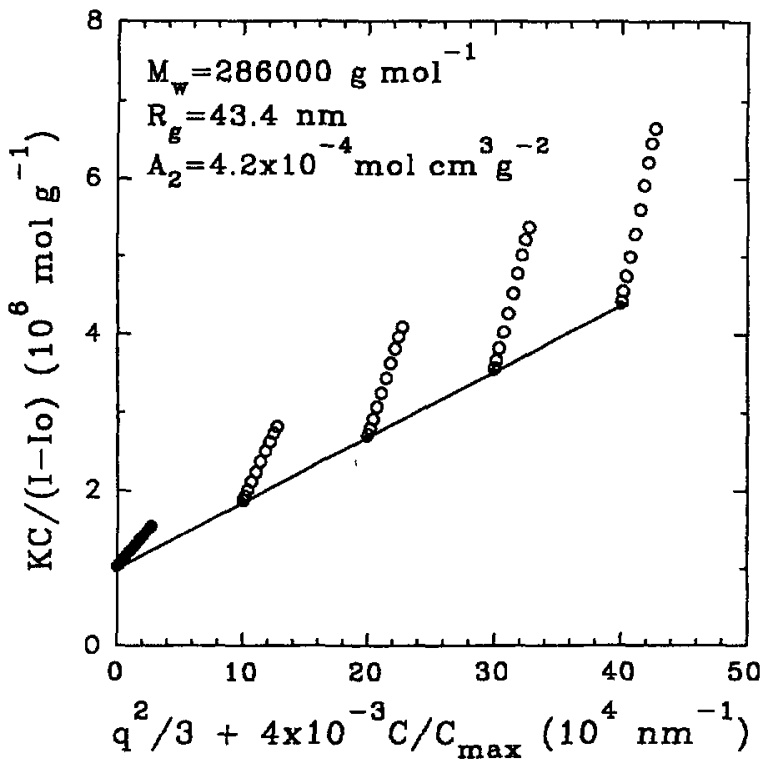

Fig. 3. - Classical Zimm-Plot obtained in the case of a solution of a polystyrene sample in toluene. Four concentrations have been used $\left(C 1=4.0 \mathrm{mg} \mathrm{cm}{ }^{-3} ; C 2=3.0 \mathrm{mg} \mathrm{cm}{ }^{-3} ; C 3=2.0 \mathrm{mg} \mathrm{cm}^{-3}\right.$; $C 4=1.0 \mathrm{mg} \mathrm{cm}^{-3}$ ).

\section{Results}

4.1. Manual Mode. - We have measured three monodisperse polystyrene samples in toluene and $\mathrm{THF}$ at $20^{\circ} \mathrm{C}$. The solutions were made dust free by fitration through Anatop filters with $0.2 \mu \mathrm{m}$ pore size. In each case four different concentrations were measured and Zimm plots were constructed. The scattered light has been measured during 1 minute for each sample. The Zimm plot for one sample in toluene is shown in Figure 3. The dependence with concentration of the specific viscosity $\left(\eta_{\mathrm{sp}}=\frac{1}{C} \frac{t-t_{0}}{t_{0}}\right)$ of the same sample is shown in Figure 4 .

The results are summarized in Table I. The molar masses determined in two different solvents agree well and illustrates the reproducibility of the measurements. The second virial coefficients are close to the values calculated using the relation $A_{2}=10^{-2} M^{-0.25}$ derived from data given by Miyaki et al. [10]. The radius of gyration of the lower molar mass sample is too small to be determined by LS. The radii of the higher molar mass samples measured in THF are in good agreement with the value calculated using the relation $R_{\mathrm{g}}=0.012 M^{059}$ given by Miyaki et al. [10]. The intrinsic viscosities in THF are in good agreement with the relation $[\eta]=0.0145 M^{0.7}$ given by Busnel [11]

4.2. Automatic Mode. - The combined detector was placed at the end of the chromatographic chain (Fig. 5). This was as usual composed of a solvent reservoir, a pump (Gilson 302 Model), an automatic injection system (Waters WISP 710B), columns and a refractometric detector (Waters R410). We used for this study two columns from Polymer Laboratories (PL Gel MIX-34-22 and MIX-B-72-8, each $600 \times 7.5 \mathrm{~mm}$, particle diameter $10 \mu \mathrm{m}$ ). The flow rate was $1 \mathrm{~cm}^{3} \mathrm{~min}^{-1}$ and injected volume $300 \mu \mathrm{l}$. Injected concentrations were around $10^{-3} \mathrm{~g} \mathrm{~cm}^{-3}$, 


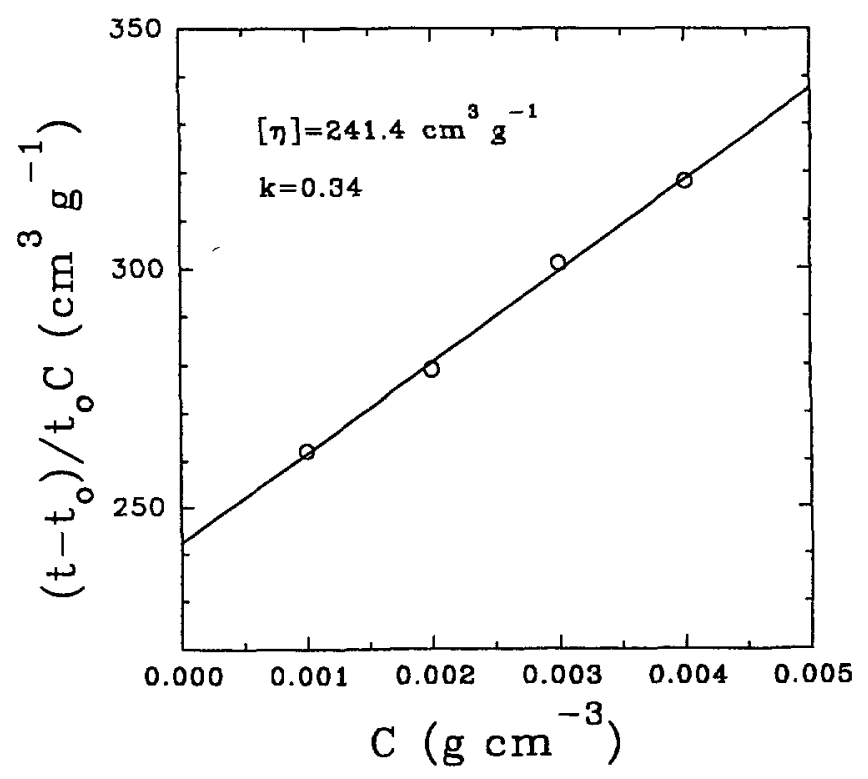

Fig. 4. - Plot of $\left(\frac{1}{C} \frac{t-t_{0}}{t_{0}}\right)$ versus $C$ for the same sample than in Figure 3 .

Table I. - Measured characteristics of three monodisperse polystyrene samples in toluene and THF, using the manual mode.

\begin{tabular}{|c|c|c|c|c|c|c|c|c|c|}
\hline $\begin{array}{c}M_{\mathrm{w}} \\
\left(\mathrm{g} \mathrm{mol}^{-1}\right) \\
\text { THF } \\
\end{array}$ & $M_{\mathrm{w}}$ & $\begin{array}{c}A_{2} \\
\left(\mathrm{~cm}^{3} \mathrm{~mol} \mathrm{~g}^{-2}\right) \\
\text { THF } \\
\end{array}$ & Tol & $\begin{array}{c}R_{\mathrm{g}} \\
(\mathrm{nm}) \\
\mathrm{THF}\end{array}$ & Tol. & $\begin{array}{c}{[\eta]} \\
\left(\mathrm{g} \mathrm{cm}^{-3}\right) \\
\text { THF } \\
\end{array}$ & $\begin{array}{l}{[\eta]} \\
\text { Tol }\end{array}$ & $\begin{array}{c}k \\
\text { THF }\end{array}$ & $\begin{array}{c}k \\
\text { Tol }\end{array}$ \\
\hline 1097000 & 986000 & $4.0 \mathrm{E}-4$ & $4.2 \mathrm{E}-4$ & 40.4 & 43.4 & 2315 & 241.1 & 0.36 & 0.34 \\
\hline 112300 & 108600 & $6.0 \mathrm{E}-4$ & $5.0 \mathrm{E}-4$ & 12.6 & 16.3 & 49.1 & 51.2 & 0.39 & 0.36 \\
\hline 43300 & 45870 & $6.2 \mathrm{E}-4$ & $8.3 \mathrm{E}-4$ & 1 & 1 & 25.7 & 27.2 & 0.41 & 0.37 \\
\hline
\end{tabular}

and the eluent was THF. The total experimental duration was 53 minutes, and the fractions were collected during periods of one minute which corresponds to volumes of $1 \mathrm{~cm}^{3}$. In these conditions, the polydispersity due to the finite size of the fractions is less than 1.03 and the overall polydispersity is less than 1.1 .

In order to test the reliability of the on-line detection we have measured 5 highly monodisperse polystyrene standards. As the samples are monodisperse, only the average values of the molar mass, radius of gyration and intrinsic viscosity can be obtained, see Table II. In Figure 6 the molar mass dependence of the radius of gyration and the intrinsic viscosity is compared with the relations found in the literature given above. The good overall agreement of the experimental data with results from the literature, indicates that the differences between the 


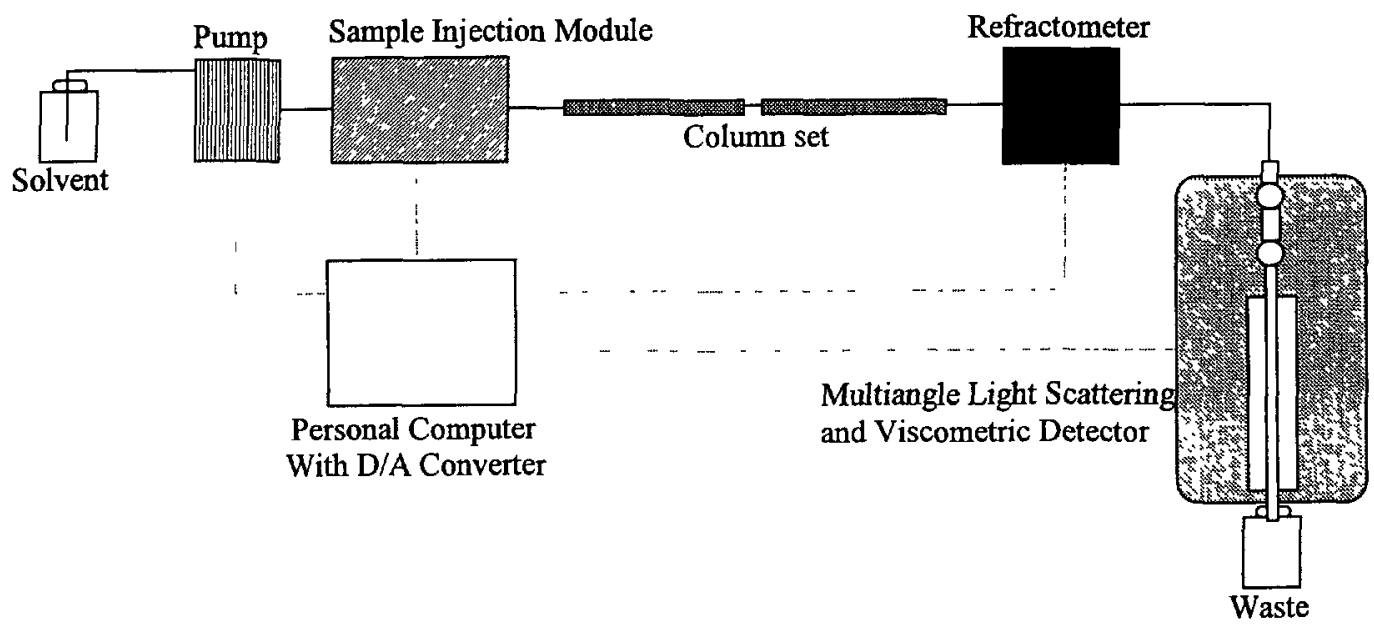

Fig. 5. - General organisation of the chromatographic chain including Multiangle Light Scatterıng and Viscometric Detector.

Table II. - Measured characteristics of five monodisperse polystyrene samples in THF, using the automatic mode.

\begin{tabular}{|c|c|c|c|}
\hline Sample & $M_{\mathrm{W}}\left(\mathrm{g} \mathrm{mol}^{-1}\right)$ & {$[\eta]\left(\mathrm{cm}^{3} \mathrm{~g}^{-1}\right)$} & $R_{\mathrm{g}}(\mathrm{nm})$ \\
\hline Press $110 \mathrm{~K}$ & $116 \mathrm{~K}$ & 51.1 & 10.8 \\
\hline Press $230 \mathrm{~K}$ & $192 \mathrm{~K}$ & 73.2 & 15.5 \\
\hline Press $390 \mathrm{~K}$ & $389 \mathrm{~K}$ & 119.1 & 23.9 \\
\hline W.Ass. 650K & $850 \mathrm{~K}$ & 204.0 & 38.6 \\
\hline W.Ass. 2.6M & $2.2 \mathrm{M}$ & 405.0 & 72.6 \\
\hline
\end{tabular}

measured molar masses and the nominal values for some samples are probably due to errors in the latter.

Figure 7 shows a comparison of the RI, VS and LS at $\theta=90^{\circ}$ normalized chromatograms for a polydisperse commercial polystyrene sample (PSJ, Jansen, Pr. Nb. 18,142-7). In this Figure, $H$ represents the high of the chromatogram, $H_{0}$ the level of the baseline, and $H_{\mathrm{s}}$ the high at the top of the chromatogram. Although gaps between detectors were carefully determined, the signals do not superimpose due to the different weighing of the signals by the molar mass: the RI signal is proportional to concentration $(C)$; the VS signal is proportional to the product $C M^{a}$ (where $a$ is the Mark-Houwink exponent); and the LS signal is proportional to $C M$.

In the Guinier domain the excess scattered light intensity $\left(I-I_{0}\right)$ or the inverse quantity is linearly related to the square of the scattering wave vector [12] $\left(q=\frac{4 \pi n}{\lambda} \sin \left(\frac{\theta}{2}\right)\right.$ with $n$ the refractive index of solvent, $\lambda$ wave length of the light). This is illustrated for sample PSJ in Figure 8 where the inverse of the average excess intensity of a fraction close to the peak 


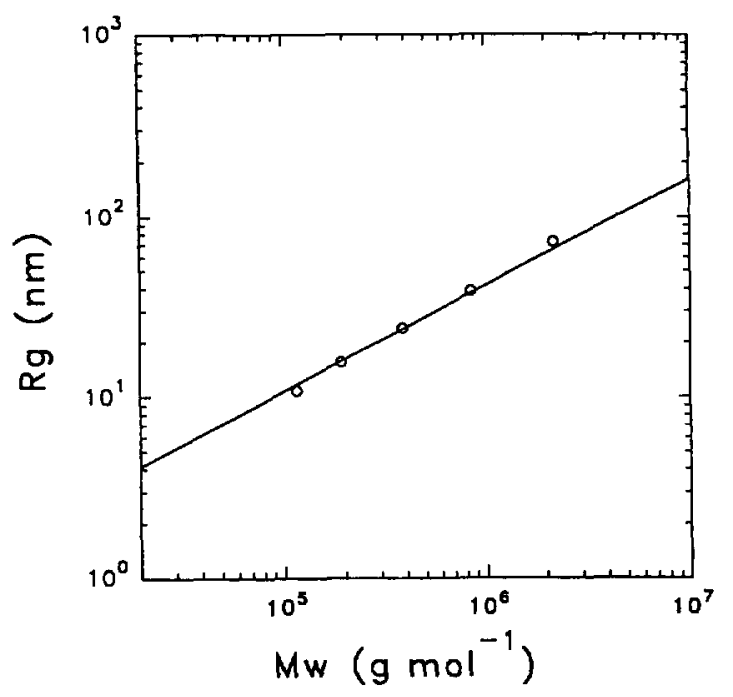

a)

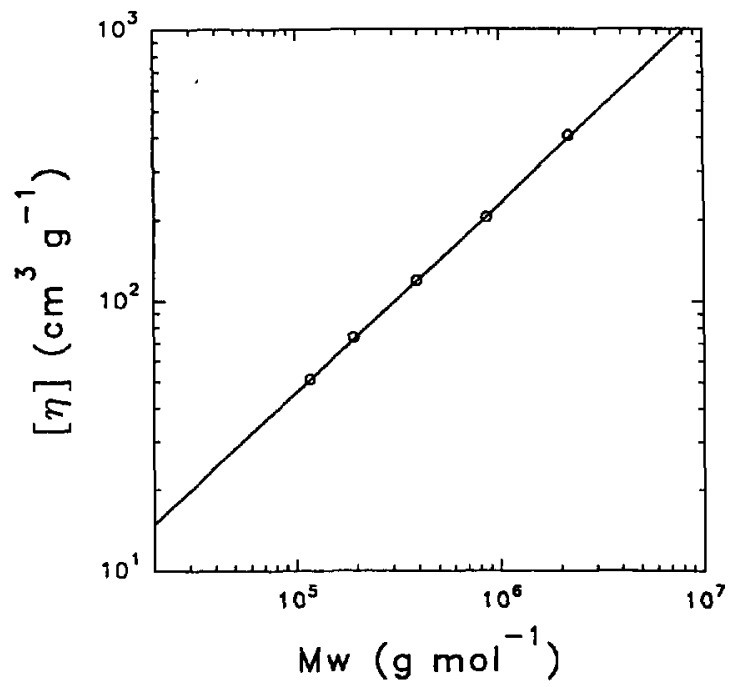

b)

Fig. 6. - Molar mass dependence of the radius of gyration a) and intrinsic viscosity b) for polystyrene in $\mathrm{THF}$, as compared with relations found in literature (see text).

position is plotted as a function of $q^{2}$ for one of the central cells of the chromatogram. This linear dependence shows that for this sample the Guinier domain $\left(q R_{\mathrm{g}}<1\right)$ is valid over the whole $q$-range. A precise determination of $R_{\mathrm{g}}$ and $[\eta]$ molecular weight relationships is only possible for samples with very broad molecular weight distribution. 


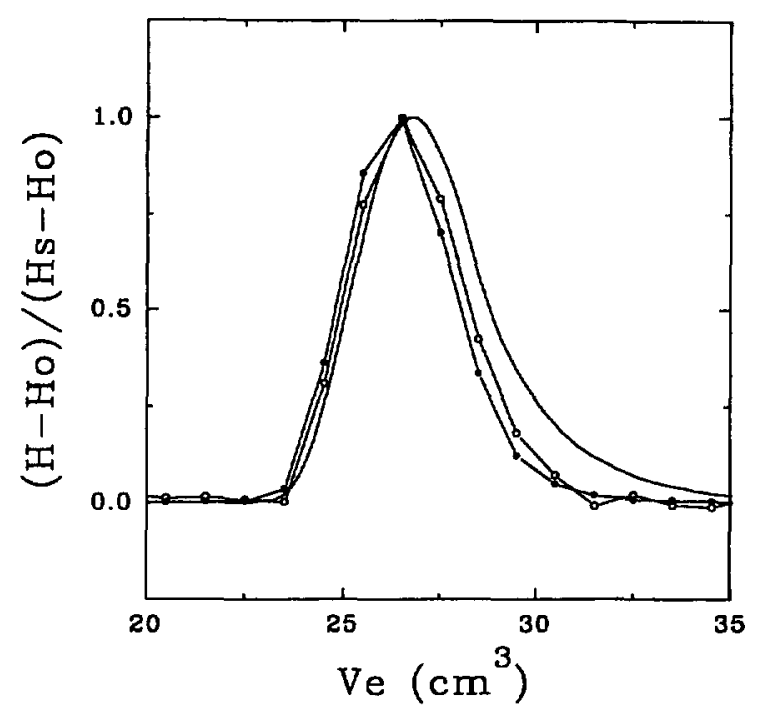

Fig. 7. - Comparison of refractometric, viscometric and $90^{\circ}$ light scattering chromatograms, in the case of a commercial polystyrene sample (Jansen, Pr. Nb. 18,142-7).

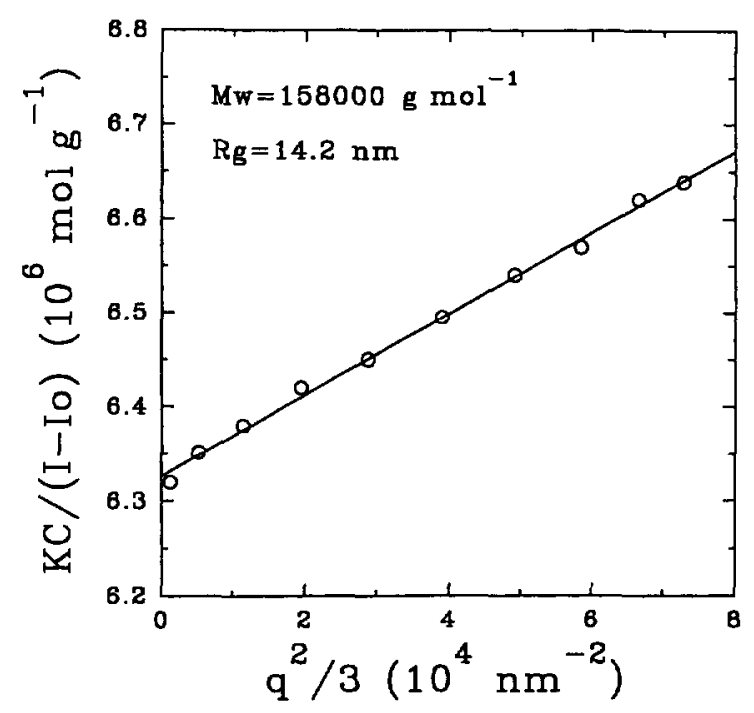

Fig. 8. - Same sample as for Figure 7. Angular dependence $K C /\left(I-I_{0}\right)=f\left(q^{2}\right)$ for the fraction eluted from 26 to $27 \mathrm{~cm}^{3}$.

\section{Summary}

We have developed a new type of combined detector Multiangle Light Scattering - Viscometry which can be used to determine a number of characteristics of polymers in dilute solution $(M$, $\left.[\eta], R_{\mathrm{g}}\right)$. The apparatus can be used separately or as an on-line detector in a SEC chain. In 
the latter case, it provides for a given sample the evolution of $M, R_{\mathrm{B}}$ and $[\eta]$ as a function of elution volume. In favourable cases, it is then possible to establish molar mass dependence of the intrinsic viscosity and the radius of gyration. A specific calibration curve is easily obtained for each analysed sample. This curve can be used to determine, for any sample of the same nature, the exact molecular weight distribution without the need to use the combined detector. Independently, the molecular weight can be obtained by application of universal calibration as proposed by Benoit [12]. In that case only viscometric measurements are used.

In addition, the combined detector offers the possibility to collect dilute fractions of about $1 \mathrm{~cm}^{3}$. These fractions can be used for further characterization using other techniques (eg, quasi elastic light scattering).

The functioning and performances of the apparatus are illustrated by a number of measurements on polystyrene samples. Additional experiments on a variety of polymeric systems both in THF and in water have been conducted and will be discussed elsewhere.

\section{References}

[1] Grubizic Z., Rempp P. and Benoit H., A unversal calibration for Gel Permeation Chromatography, J. Polym. Scr. Polym Lett. 5 (1967) 757.

[2] Orvoen J-B. and Busnel J-P., Evaluation des performances d'un nouvel analyseur viscosimétrique en ligne pour chromatographie d'exclusion stérique, Spectra 13 (1985) 104.

[3] Ouano A.C., Gel permeation chromatography VII. Molecular weight detection for SEC effluents, J. Polym. Scr. Symph. 43 (1973) 299.

[4] Letot L., Lesec J. and Quivoron C., Performance evaluation of a continuous viscometer for high speed GPC, J. Liq. Chrom. 3 (1980) 427.

[5] Haney M.A., The differential viscometer II. On-line viscosity detector for size-exclusion chromatography, J. Appl. Polym. Sci. 30 (1985) 3037.

[6] Ouano A.C. and Kaye W., Gel permeation chromatography X. Molecular weight detection by Low Angle Laser Light Scattering, J. Polym. Scr. A1 12 (1974) 1151.

[7] Virloget J.M., Apparatus for detecting the level in automatic capillary tube viscometer, Canadian Patent $\mathrm{N}^{\circ} 1006599$ (1977).

[8] Zimm B.H., The scattering of light and the radial distribution function of high polymer solutions, J. Chem. Phys. 16 (1948) 1093.

[9] Degoulet C., Nicolai T., Durand D. and Busnel J.-P., Characterization of Polydisperse Solutions of Branched Polymethyl Methacrylate using Size Exclusion Chromatography with On-lıne Multi-Angle Light Scattering and Viscosity Detection, Macromolec. (in press).

[10] Miyaki Y.. Einaga Y. and Fujita H., Excluded - volume effects in dilute polymer solutions. 7. Very high molecular weight polystyrene in benzene and cyclohexane, Macromolec. 11 (1978) 1180.

[11] Busnel J-P., Data handling in G.P.C for routine operations, Polymer 23 (1982) 137.

[12] Huglin M.B., Light Scattering from Polymer Solutions (Academic Press, London, 1972).

[13] Benoit H., Grubizıc Z., Rempp D., Dekker D. and Zilliox G., Etude par chromatographie en phase liquide de polystyrenes lineaires et ramifiés de structures connues, J. Chım. Phys. 63 (1966) 1507. 